\title{
Online teaching in Education for the subject group History under COVID 19 conditions
}

\author{
DOI: http://dx.doi.org/10.17159/2223-0386/2021/n25a4
}

\section{Byron Bunt}

North-West University, Vanderbijlpark, South Africa

Byron.Bunt@nwu.ac.za

Orcid: 0000-0002-2102-4381

\section{Abstract}

As tertiary institutions globally transitioned into an online teaching framework as a consequence of the Covid-19 pandemic, it is critical that history education lecturers reconsider their teaching and learning strategies. This article reports on the planning and implementation of an online teaching programme within the History in Education subject group at the North-West University (NWU), in South Africa. The author is the subject group leader of the subject group and from observations and experiences, this article will report on how this program was implemented. First and foremost, how we handled teaching in an online setting is vastly different from a face-to-face setting. Few lecturers might have taught students studying in distance programs for some time, but for many lecturers and students who are accustomed to face-to-face instruction, the online world may often be new and even intimidating. The existing scenario calls for a full rethink in teaching and learning. Through proper preparation, we will not only provide our lecturers through greater versatility in the delivery of online classrooms, but also represent our students when making the best of the opportunities we have at our disposal. This article wishes to undertake a critical experiential evaluation of this online teaching strategy that was used in 2020 in the History Education subject group at the North-West University. A literature review focusing on online teaching, History in Education online teaching as well as COVID-19's impact on tertiary education. The methodology of the research is then discussed, followed by the initial planning stage, culminating in the lessons learned and possible future changes to this plan.

Keywords: Distance education; Online learning; Remote teaching 


\section{Introduction, background and context}

Anyone who has ever worked in a conventional classroom setting as a teacher or facilitator knows first-hand that with different classes or individual learners, the same content will never yield the same results (Shahabadi \& Uplane, 2015:132). In addition, information may be relevant to the learning style of an individual, while the same information may be worthless in fulfilling the learning goals of another individual (Masie, 2002; Zenger \& Uehlein, 2001:56). In response to this empirical reality and it's ramifications for teaching material delivery through online platforms, researchers may argue that, in the end, it is the behavioural indicators of students that must be considered when creating and implementing e-learning programmes to develop Self Directed Learning (Shahabadi \& Uplane, 2015:132). Consequently, the researcher agrees with Codreanu and Vasilescu (2013) that the emphasis is on the students and their needs and requirements; it is crucial to evaluate the effect on any programme developed and delivered through internet-based technology. From this point on, we will use the broad term of e-learning.

Rosenberg and Foshay (2002:51) described e-learning:

"as the use of information communication technology to provide information and guidelines to individuals, predominantly via the intranet or the Internet. Research has shown that, while terminology such as computer-based learning, remote learning, digital learning or webbased training is sometimes used, e-learning will ultimately prevail as most organisations preferred concept."

There are a number of synchronous e-learning types. Shahabadi and Uplane (2015:131) describe "synchronous e-learning [as] live, real-time (and usually scheduled), facilitated instruction and learning-oriented interaction. In this type of learning, learning experiences are in real-time." Another popular method of synchronous learning includes actual 'chat' sessions when students sign in simultaneously to collaborate on certain themes (Shahabadi \& Uplane, 2015:131).

Today, the bulk of e-learning is asynchronous in nature. Shahabadi and Uplane (2015:132) describe "asynchronous e-learning as comparable to synchronous e-learning in a general sense which is a learner-centred process, which uses online learning resources to facilitate information sharing regardless of the constraints of time and place among a network of people." Asynchronous e-learning has the benefits of computer-mediated 
communication (CMC) "to achieve the promises of learning anytime and anywhere through asynchronous online discussions, which is based on the constructivist theory, a learner-centred approach that emphasises the importance of peer-to-peer interactions" (Shahabadi \& Uplane, 2015:132). The researcher argues that in an online environment, the system needs to cater for learner-centredness, which is embedded in constructivist theory, as alluded to above. The researcher utilised this asynchronous method in this project, by using screen casting or interactive PDFs and PowerPoints of study units, which has been pre-recorded for students. Less prominent is synchronous e-learning, which is 'absolute' and necessitates all participants to be in front of their computers at the same time. This method was difficult to follow due to a lack of infrastructure. A mixture of technology and classroom-based learning are used for blended classes, or 'blended learning,' and is becoming a prevalent method for teaching (Mahaye, 2020:10; Masie, 2002; Zenger \& Uehlein, 2001:56). However, due to the nature of the teaching and learning during the COVID-19 pandemic, the university opted for a fully online remote teaching strategy, as no classroom-based learning could be used.

The manner in which the program was implemented was asynchronous, as not all students had access to data or hardware. All assessment tasks were communicated at least a month in advance, to give students sufficient time to complete them.

To keep students interested, multiple interactive strategies (e.g. hyperlinks and buttons) have been implemented for the student to engage with the module content (Subandi, Choirudin, Mahmudi, Nizaruddin \& Hermanita, 2018: 246). Engagement and understanding, including multiple choices and transfer files, are also encouraged by different modes of instruction.

Comer and Lenaghan (2013:262) argued that asynchronous online learning offers an excellent probability to build a learning-centred surrounding that stimulates rich interactions between lecturers and students and among students. Through an online asynchronous panel, "computer and internet technologies enable communication via the generation of discussion messages amongst participants" (Han \& Hill, 2006:30), that will generate more constructive engagement and connection compared to many conventional face-to-face environments.

\section{COVID-19 and move to online teaching}

As a result of the COVID-19 pandemic lockdown, tens of thousands of schools in South Africa were suspended in 2020, as was the case in many other countries around the 
world. While schools started partially reopening later that year, severe controls remain in place, and predicting when the closures will end completely appears to be difficult at present. As a result, teachers face major difficulties in transitioning to online education, ensuring a minimum level of contact with students, and promoting students' learning and growth. However, it is unclear how well teachers have handled these difficulties and the considerations are most important.

The COVID-19 pandemic has created unparalleled obstacles for students, forcing them to transition to teaching online. Until March 2020, the traditional school teaching situation was characterised by students congregating in classrooms according to their timetables and teachers covering the regular content of their subjects, often by structured lecturing. Students were expected to pay attention to their instructors, act alone or in groups, and primarily reproduce information in tests. In comparison, ICT use was limited (Fraillon et al., 2019).

While the transition to online instruction was sudden and swift as a result of COVID-19, it occurred as part of a larger ICT transformation phase in educational systems (Selwyn, 2012; McFarlane, 2019). Digitalisation in classrooms has increasingly gained popularity. A main concern applies to narrowing the 'gap' between students' traditional development and learning at school and "the experiences and skills that our youth need to enter the information economy" (Kozma 2011:106). The school curriculum should be increasingly interwoven with ICT, and students should be given the opportunities to use advanced technological tools and digital resources for creative and interdisciplinary work (Kozma 2011:115).

\section{Research Methodology}

In this study, an autoethnographic methodology was employed. According to Maréchal (2010:43), "Autoethnography is a form or method of study that includes self-observation and reflexive investigation in the sense of ethnographic field work and writing." Carolyn Ellis (2004:9), another well-known autoethnographer, describes it as "research, writing, narrative, and process that relate the autobiographical and personal to the cultural, social, and political." However, reaching an agreement on the meaning of the word is difficult.

In the 1970s, for example, autoethnography was loosely described as "insider ethnography," relating to studies of the (culture of) society of which the researcher is a participant (Hayano, 1979). However, as Ellingson and Ellis (2008:449) point out, "the definitions and uses of autoethnography have changed in such a way that accurate 
classification has become difficult."

Autoethnography differs from conventional ethnography, a social science approach used by anthropologists and sociologists, in that it accepts and emphasizes the researcher's subjectivity rather than suppressing it. If ethnography is commonly thought of as a qualitative approach in the 'social sciences' that explains human social phenomena through fieldwork, autoethnographers are the primary participant/subject of the study in the process of writing personal stories and narratives.

Autoethnographers shed light on their complete engagement with the environment by making their every emotion and thinking clear to the reader by embracing personal opinions, emotions, stories, and perceptions as a means of explaining the social context they are researching. This is diametrically opposed to theory-driven, hypothesis-testing analysis approaches focused on positivist epistemology.

In this context, Ellingson and Ellis (2008) regard autoethnography as a social constructionist project that denies the deeply embedded binary oppositions between the researcher and the studied, objectivity and subjectivity, method and product, self and others, art and science, and the intimate. This study used my experiences as a lens, where I report on what I have seen throughout the entire process of migrating to online learning in 2020. Through this process, observational qualitative research was employed. Among qualitative data collection methods, direct observation has been defined as the gold standard (Murphy \& Dingwall, 2007).

Observing individuals in their natural habitat not only removes the issues associated with self-reported accounts (Mays \& Pope, 1995), but may also expose insights not available by other data collection techniques, such as systems, procedures, and activities that interviewed participants might be unaware of (Furlong, 2010). Methods of observation include directly witnessing and tracking how research participants interact within, and react to, their physical and social world as it happens (Mays \& Pope, 1995; Mulhall, 2003).

Observation "provides insight into relationships between behaviours and groups; highlights the overall picture; records context/process; and communicates about the effects of the physical environment" (Mulhall, 2003:307). Approaches to observation differ depending on the research's political perspective and the position participants take on the spectrum from observer to sample (Walshe, Ewing \& Griffiths, 2012). Observation approaches range from non-participant observation, in which the observer has no further relationship with the group being observed, which includes shadowing (Quinlan, 2008), to participant observation, in which the researcher is also a member of the team being examined (Bloomer, Cross, Endacott, O’Connor, \& Moss, 2012). In this study, I was a 
participant observer, who was a part of the team.

Methods of documenting vary from formal template recording to unstructured field noting (Walshe et al., 2012). More significantly, video-recording methods have proven to be an effective means of capturing findings (Carroll, Iedema, \& Kerridge, 2008; Collier, Phillips, \& Iedema, 2015; Cronin, 2014; Forsyth, Carroll, \& Reitano, 2009; Iedema, Merrick, Rajbhandari, Gardo, Stirling, \& Herkes, 2009). In this study, field notes were taken, as well as video recordings of methods used. The field notes were mostly taken from minutes of school and subject group meetings, in which the new procedures for moving to an online learning environment were discussed. Policy guideline documents as well as workshop presentations from experienced academics were also utilized to make informed decisions on adapting teaching and learning to this new approach. Personal conversations were held with the school director, as well as other academic staff who are a part of the History in Education subject group, regarding their experiences of the online teaching shift. Video recordings of mine as well as other colleagues' online lessons were also scrutinized, as well as the assessment tasks posted on the LMS. In analysing this anecdotal data, the researcher reflected on how the system was put into place at the onset of remote online teaching. Afterwards, another reflection took place to see what worked and what did not work, and how the system can be improved.

\section{Conceptual framework}

\section{Distance education}

Distance learning is the umbrella word for all learning that takes place over distance and not in a conventional classroom (Fırat, Kılınç \& Yüzer, 2018:63 - 70). Distance learning has a long tradition, and many forms are available today. These include: email discourses that are conducted via daily mail with no contact; telecourses, where the material is broadcasted on radio or television; CD-ROM courses, where the content is stored on a static device; online learning, where classes are delivered either synchronously or asynchronously; and mobile learning, using platforms such as smart phones or portable audio players (iPods, MP3 players, etc.) (Firat et al., 2018:63 - 70).

\section{Online learning}

Online learning includes enrolling in an online course and learning through online lessons 
and assignments. Online education has increased in popularity over the past few years, empowering students to learn at home and in their own time (Dhawan, 2020:5 - 22). The benefits of online learning are that it is very easy and helps students to live a regular life and hold a career while studying. Online learning is also more accessible; it is convenient for adults who have a busy lifestyle. Online learning allows one to learn anywhere in the world as long as a secure internet connection is maintained. There is no need to leave a job and one can continue to make a living as courses are completed online. Online learning can save time and money, including by removing or limiting travel costs, and normally allows students to learn at their own pace. However, some negative aspects of online learning include that not all courses are offered online, and that there is no intimate connection between the student and the lecturer. Maintaining a secure internet connection and a compatible computer is needed to access these courses. Without the lecturer making constant contact with you, it is easy to give up on your online research (Dhawan, 2020:5 - 22).

\section{Remote teaching}

In comparison to the experience that has been prepared from the start and built to be online, emergency remote teaching (ERT) is a temporary change from instruction delivery to substitute delivery due to disaster circumstances (Hodges, Moore, Lockee, Trust \& Bond, 2020:1 - 12). It includes the use of entirely remote teaching solutions for training or curriculum that may otherwise be provided face-to-face or as mixed or hybrid courses, and that can revert to the original model after the situation or emergency has ended (Hodges et al., 2020:1-12). The primary goal in these situations is not to re-create a robust educational environment, but rather to provide temporary access to education and preparation in a manner that is easy to develop and reliably accessible during an emergency or disaster. If we interpret ERT in this way, we can start to distinguish it from "online learning" (Hodges et al., 2020:1-12).

\section{Proposed plan at the beginning of the COVID-19 pandemic}

\section{Learning Management System (LMS) page}

The Learning Management System used at NWU is called eFundi. It integrates various tools such as chat rooms, online testing and resource management, to make online teaching more 
efficient. Each module and LMS module page were developed and effectively maintained as the LMS is the cornerstone of the online environment (Weaver, Spratt \& Nair, 2008). Most students were acquainted with the LMS site; however, management urged each instructor to create a brief video to help students if they needed new resources that they have not used before. This was sent to WhatsApp or Telegram using the Notification Platform or Chat Groups.

Since lecturers did not see their students frequently in the classroom, it was vitally crucial that a very straightforward semester schedule be provided for each LMS module site to ensure that students knew at all times what was going to happen in each module and when it was going to happen. Students considered it incredibly useful if lecturers updated this program again at the beginning of each week through a notification or in the chat groups, so that the students were aware of it and could follow the work schedule (Weaver et al., 2008). The semester schedule contained projects or assessments that were sent for evaluation. This was also helpful for students when the semester schedule specified which presentations would be submitted and which study units would be completed as part of the student's self-directed learning cycle.

The Learning Management System was the primary tool for students. Lecturers concentrated on the successful usage of the LMS to provide all students the ability to obtain content, providing the greatest opportunities for all students to excel (Ip, Morrison, Currie \& Mason, 2000). Lecturers were required to upload information to make it easier for them to access certain tools. The lecturers need to communicate clearly that the students can search for anything on the LMS.

The use of the Polls feature to post a question(s) to find out how students feel about a particular topic was very useful. If the lecturers did not want to use external apps (for which students would require data), the wiki platform was a fantastic resource for students to work together and generate their own content (Ip et al., 2000). 
Image 1: Below is an example of an assessment plan that included the aspects mentioned in this section:

\begin{tabular}{|c|c|c|c|c|}
\hline \multicolumn{5}{|c|}{ Module and assessment plan HISD 512} \\
\hline Week & $\begin{array}{l}\text { Assignment to } \\
\text { be submitted for } \\
\text { assessment }\end{array}$ & $\begin{array}{l}\text { Submission } \\
\text { date of } \\
\text { assignments }\end{array}$ & $\begin{array}{l}\text { Self-directed } \\
\text { learning }\end{array}$ & $\begin{array}{l}\text { PowerPoint } \\
\text { presentations }\end{array}$ \\
\hline $20 / 04-24 / 04$ & $\begin{array}{l}\text { Assignment - } \\
\text { Source-based } \\
\text { essay }\end{array}$ & $24 / 04$ & $\begin{array}{l}\text { Review study } \\
\text { units completed } \\
\text { up to date. }\end{array}$ & \\
\hline $27 / 04-01 / 05$ & $\begin{array}{l}\text { Feedback on } \\
\text { Essay }\end{array}$ & $01 / 05$ & $\begin{array}{l}\text { Study Unit 4: } \\
\text { sections } 1 \text { and } 2\end{array}$ & $\begin{array}{l}\text { PowerPoint } \\
\text { with voice-over } \\
\text { on LMS }\end{array}$ \\
\hline $04 / 05-08 / 05$ & $\begin{array}{l}\text { Unit 4: } \\
\text { Assignment } 2.1\end{array}$ & $15 / 05$ & $\begin{array}{l}\text { Study Unit 4: } \\
\text { sections } 3 \text { and } 4 \\
\text { and Study Unit } \\
\text { 5: section } 1\end{array}$ & $\begin{array}{l}\text { PowerPoint } \\
\text { with voice-over } \\
\text { on LMS }\end{array}$ \\
\hline $11 / 05-15 / 05$ & & & $\begin{array}{l}\text { Study Unit 5: } \\
\text { section } 2\end{array}$ & $\begin{array}{l}\text { PowerPoint } \\
\text { with voice-over } \\
\text { on LMS }\end{array}$ \\
\hline $18 / 05-22 / 05$ & $\begin{array}{l}\text { Digital jigsaw } \\
\text { collaborative } \\
\text { activity }\end{array}$ & $22 / 05$ & & $\begin{array}{l}\text { Power-Point } \\
\text { with voice-over } \\
\text { on LMS }\end{array}$ \\
\hline $25 / 05-29 / 05$ & & & $\begin{array}{l}\text { Review all work } \\
\text { done during } \\
\text { the semester, } \\
\text { work on exam } \\
\text { assignments } \\
\text { and prepare for } \\
\text { the exam. }\end{array}$ & Study group \\
\hline
\end{tabular}




\section{Web resources}

Other web resources can, however, be used. For History Education it was vital to obtain any Open Education Resources (OER) that could be found and were relevant to the topics presented to students. Several forms of resources were obtained, including videos, articles, cartoons, maps and photos. These were used as teaching and learning support material in the online setting.

Regarding the use of web material, it was quite easy to find numerous open educational resources, from websites such as https://www.teachithistory.co.uk/, https://www. teachinghistory.org/, as well as https://www.oercommons.org/, that were quickly adapted for the subject group's needs. The ability to share these resources easily on the university LMS allowed the subject group to tailor assessments that were aligned across all campuses and all modes of delivery, including distance learning. This, from a lecturer perspective, made things extremely simple, however, the same cannot be said for the students who had to access this material. That is discussed in the following section.

\section{Communication}

Constructive and continuous contact is the secret to online education (Lamy \& Hampel, 2007). Types of resources that may be used for this function include LMS chat conversations, community forums on LMS, WhatsApp/Telegram (it is important to not use your personal number or anonymise your phone number) or online face-to-face applications such as Zoom, Google Meets, Skype, and so forth.

WhatsApp and Telegram were also a wonderful way to easily supply short videos to the students to provide them with positive and quick support (Lamy \& Hampel, 2007). When using WhatsApp or Telegram, it is necessary to have specific guidelines, such as times when students may ask questions. Therefore, setting restrictions on when and how often students can communicate with the lecturer was crucial. Lecturers could also use the Google Suite Communication Apps should they choose to set up project workgroups, such as Google Docs, which allowed for synchronous editing and commenting on a single document shared between student groups. Good contact between lecturers and students is often assured by frequent LMS updates that are relevant to students and their learning (Lamy \& Hampel, 2007). 
Again, this entailed preparation for lecturers, because not all lecturers were familiar with the groups and community conversations on the LMS site. Most lecturers are still ignorant of the large range of multimedia outlets that may be used for digital interactions.

\section{Study groups}

It was important to encourage the students to set up virtual study groups. Students were comfortable because they learned together and collaborated together (Brindley, Blaschke \& Walti, 2009). Most students were also part of communities that exchanged research, resolved topics of interest in the academic community and encouraged each other (Brindley et al., 2009). For example, there were current WhatsApp Groups in the BEd Intermediate Process for each year group. When having a student mentor and WhatsApp or Telegram communities, make the student mentor part of this community so that your assistant may help them and keep the lecturer aware of anything that the students might be dealing with (Brindley et al., 2009).

The study groups comprised of between four and six students per module, but the composition of these groups changed per assessment task, to allow students to work with different people on different tasks. All Google Docs links were shared between students on the WhatsApp groups, so that all members could participate in editing and commenting on their work.

\section{Video recordings}

The video clips mentioned here would be specific for each lecturer. It was recommended that the lecturer capture at least one presentation for each study unit that he/she has in the study guide for that specific section (Hartsell \& Yuen, 2006). This was normally about 20 minutes, not to burden the students with long presentations where they lose focus. The amount of content normally dictated the number of recordings, as each unit would require some video recording.

\section{Software that were used included: Please see overleaf}




\begin{tabular}{|c|c|c|}
\hline Software & Use & Keep in mind \\
\hline $\begin{array}{l}\text { PowerPoint - } \\
\text { Record slide } \\
\text { show }\end{array}$ & $\begin{array}{l}\text { With the record } \\
\text { slide show } \\
\text { option lecturers } \\
\text { could record } \\
\text { themselves while } \\
\text { presenting the } \\
\text { PowerPoint. }\end{array}$ & $\begin{array}{l}\text { The students may have an older PowerPoint so it } \\
\text { was best to save the recording as a mp4 to make } \\
\text { sure that they will be able to open it. } \\
\text { Recommended not to make } 40 \text { min recordings. } \\
\text { Remember these students are sitting at home. } \\
\text { They could be distracted. If lecturers record } \\
\text { a } 40 \text { min session, the students would not sit } \\
\text { through it. Rather break it up in short sections. In } \\
\text { addition, for consideration, voice recordings on } \\
\text { WhatsApp to talk students through a short Pow- } \\
\text { erPoint presentation as much less data was used } \\
\text { and the voice recording may be easily accessible } \\
\text { on the smart phone. It was important to commu- } \\
\text { nicate with them exactly in which folder to look } \\
\text { for the particular PowerPoint presentation on the } \\
\text { LMS (Hartsell \& Yuen, 2006). }\end{array}$ \\
\hline YouTube & $\begin{array}{l}\text { Live session, } \\
\text { short orienta- } \\
\text { tions of what } \\
\text { they need to } \\
\text { work on. }\end{array}$ & $\begin{array}{l}\text { The students were familiar with YouTube, the } \\
\text { lecturer could stream the class in the time they } \\
\text { would have had class or record a short orientation } \\
\text { session of what students need to work on during } \\
\text { that week. Uploading it to YouTube and making } \\
\text { the link private so that students can only access } \\
\text { it if they have the link was done. It was important } \\
\text { to keep in mind though, that not all students may } \\
\text { have had data to access YouTube (Hartsell \& } \\
\text { Yuen, 2006). }\end{array}$ \\
\hline $\begin{array}{l}\text { VideoScribe, } \\
\text { Powtoons, Doo- } \\
\text { dly and Toonly }\end{array}$ & $\begin{array}{l}\text { Make explanato- } \\
\text { ry videos }\end{array}$ & $\begin{array}{l}\text { Lecturers explained concepts to students with } \\
\text { animated videos (Hartsell \& Yuen, 2006). }\end{array}$ \\
\hline Active Presenter & Screen recorder & $\begin{array}{l}\text { Recorder that recorded the lecturers' screen } \\
\text { and webcam. This enabled lecturers to record } \\
\text { themselves while presenting their PowerPoint } \\
\text { (Hartsell \& Yuen, 2006). }\end{array}$ \\
\hline
\end{tabular}

Lecturers who had access to tablets captured their PowerPoints using a screen recorder and submitted them to the LMS. Lecturers were provided the requisite technical resources and have received training to film images on their computer screens. These videos were also posted to the LMS websites (Hartsell \& Yuen, 2006). 


\section{Activities on LMS}

The students needed to remain consistently engaged in their research during the online teaching period and not only sporadically work on tasks throughout the remainder of the semester (Ip et al., 2000). This directed the successful involvement and engagement of students in specific modules during the semester. It was recommended that students be provided smaller assessments or tasks (Meyer \& Murrell, 2014). Assessments or tasks on the LMS were assessed automatically, so that it might not present unnecessary work for the lecturer. Many programs that lecturers could use may have required the following (Weaver et al., 2008):

\begin{tabular}{|l|l|l|}
\hline Pictochart & Create Infographics & $\begin{array}{l}\text { Create infographics. Make one-page } \\
\text { explanations of what you would have } \\
\text { explained in class. }\end{array}$ \\
\hline Interactive PDF & $\begin{array}{l}\text { Create PDF's with } \\
\text { buttons }\end{array}$ & $\begin{array}{l}\text { Create PDF's that when students click } \\
\text { on spaces audio play or another file } \\
\text { open. This gets the student involved and } \\
\text { get them to engage and not only scroll } \\
\text { through the information (Meyer \& } \\
\text { Murrell, 2014). }\end{array}$ \\
\hline Google Suite & Group work & $\begin{array}{l}\text { Get your students to conduct group } \\
\text { work by creating documents where they } \\
\text { need to collaborate in a group on one } \\
\text { document. They can create webpages, } \\
\text { PowerPoint like slides and documents } \\
\text { (Meyer \& Murrell, 2014). }\end{array}$ \\
\hline Socrative & idea boards & $\begin{array}{l}\text { You can create tests that students can } \\
\text { complete at their convenience. It is better } \\
\text { to use LMS as the marks will be captured } \\
\text { in the Markbook (Meyer \& Murrell, } \\
\text { 2014). }\end{array}$ \\
\hline Online tests & $\begin{array}{l}\text { On Padlet students can post pictures, au- } \\
\text { dio and video on a topic as an assignment } \\
\text { or discussion point (Meyer \& Murrell, } \\
\text { 2014). }\end{array}$ \\
\hline
\end{tabular}




\begin{tabular}{|l|l|l|}
\hline Perusall & $\begin{array}{l}\text { Comment on docu- } \\
\text { ments }\end{array}$ & $\begin{array}{l}\text { Perusall is an online platform where stu- } \\
\text { dents can read articles and comment on } \\
\text { their peers' comments (Meyer \& Murrell, } \\
2014) .\end{array}$ \\
\hline
\end{tabular}

\section{Assessment}

It was advised that smaller assessment tasks were given, on which continuous feedback ought to have been provided to drive the learning process, that culminated in a large, summative activity with a heavier weighting (Salas-Morera, Arauzo-Azofra \& GarcíaHernández, 2012). The lecturer systematically evaluated this summative function.

Academic development was achieved where students were required to interact with the components of the curriculum on a consistent basis instead of just focusing on one or two 'major' tasks or performing a basic LMS test at a low cognitive standard for final summative evaluation. Using the peer-assessment method in the LMS, where students had to read and report about other results, not only improved their knowledge of work, but also allowed the students to learn what their peers were doing (Salas-Morera et al., 2012). It was recommended to also use longer academic essays as a major form of assessment. However, the LMS could not mark these automatically, and digital marking was required.

\section{Academic accountability}

Academic personnel were responsible for storing videos, tasks, daily messaging as a way of engaging with students and the services provided by students. Module Leaders (lecturers in charge of planning a module) were responsible for maintaining frequent, direct contact with students and for creating and uploading research notes and materials. Module Leaders were respectfully asked to engage in close cooperation with Subject Chairs (leaders of subject groups, such as the History subject group) who wished to comment on the success of the academic curriculum in a different topic area at daily meetings with the School Manager/Deputy Director (oversees a whole school, for instance, School of Commerce and Social Studies).

After each study class, a brief questionnaire was attached to the LMS page (Weaver et al., 2008) and completed by the students. It provided the Module Leader and the Subject Chair with an idea as to how the Module owner has submitted all the necessary material 
which provided the Module owner with useful statistics during the semester about whether students have viewed it in a specific class. The Module Leader and the Subject Chair were introduced to the LMS sites so that they could take care of the students' responses.

\section{Participation marks}

Just as participating in a face-to-face setting required the engagement of students in the classroom, participation must also be part of the online presence of students (Grieve, Padgett \& Moffitt, 2016). The use of the LMS polling resources, such as asking questions to get the students interested and to gauge their progress. It was not all about the lecturer simply capturing and sharing lectures; the students were involved and took responsibility for their own learning (Salas-Morera et al., 2012).

It is imperative to reconsider the significance of a participation mark in an online environment. If lecturers focus entirely on homework, they cannot be confident whether students are involved in the module, so this is why online polling resources, forums and chat rooms were important, so that live conversations became an essential aspect of the engagement level (Grieve et al., 2016). Continued participation in small learning tasks required more than one main task in an online environment (Grieve et al., 2016).

\section{Experiential reflection on what worked and did not work}

\section{What worked and why}

The use of the university LMS, eFundi, which is a university cloud storage and resource centre and online teaching tool for the NWU, worked well once everything was in place and the storage space for uploading material was increased. The university did not foresee such a demand for storage space on their LMS at first, which created a bottleneck, but fortunately, this was fixed quickly in a matter of a day or two. The IT department needed to allow more storage space for Dropbox resources, for both lecturers uploading resources, and for student downloading them. The various functions of the LMS, such as the chat room function and polling function, worked wonderfully in order to maintain communication and give feedback to students. After every essay assignment was marked, using the comment function in Adobe Acrobat Reader, whereupon I would reload the annotated essays to the LMS, I would schedule a chat room session with my students, to give them 
some more direct feedback. They engaged with me quite well, for every major assignment that was completed. In the beginning of the semester and at the end, I created a poll on the LMS, to gauge the students' views regarding online teaching and learning. In the beginning, I asked questions like "Are you prepared for online teaching?", or "Do you have stable access to the internet?" At the end, I asked questions like "How do you feel now that you have completed an entire semester of online teaching?", or "Do you think that online teaching has prepared you sufficiently to master the content and outcomes, compared to normal face-to-face teaching? Explain.” These questions changed, as in the beginning, I wanted to gauge their preparedness as a form of orientating the students, and at the end, the questions took on a more reflective form, to gauge effectiveness of the tools and methods we used in online teaching. The results of these polls were quite positive.

The use of video recordings, at first, seemed to be the answer to all the history lecturers' and students' prayers regarding presenting material to students and affording some instructor to student interaction. They did solve the problem of almost allowing the student into a virtual classroom, and it did work better than some cases of live synchronous presentations over platforms like Zoom or Google Meet, which requires a stable and fast internet connection. A vital component to making videos viable was the idea of compression, which I initiated within the faculty. The software called Handbrake was recommended, in order to curtail the issue of massive MP4 files spanning several 100 megabytes or even gigabytes, to compress them to sizes that are more acceptable.

Regarding assessment, the activities themselves remained unchanged, and diligent consideration had to be given for students concerning finding resources online, as many students did not have sufficient data or devices to download these articles. This was definitely carried out, as I would attach articles for the students on the LMS, which was given zero data access by cellular network providers. This came as a result of finally understanding that the initial almost romanticized optimistic phase of online teaching was ending. The assessments, which ranged from academic essays to more practical lesson plan activities, to methodological tasks such as creating worksheets, were all done very successfully.

One could use the analogy of a war or battle, in which the lecturers are the generals, and the students are soldiers on the front lines. The goal is to defeat an enemy, in this case, overcoming the limitations brought on by COVID-19. In battles and wars, a distinction can be made between strategy and tactics. Strategy could be compared to the overall planning stages for online teaching, the intended goals. However, strategies normally do not always work, and it is up to the generals to employ tactics IN the field, adapting to how the enemy is fighting back. So, tactics could be regarded as the practical adaptations brought on by 
online teaching that did not necessarily work out according to the battle strategy, or ideal planning. In the end, it would seem to me that the battle was won. Victory came at a cost of some casualties, with some students still not passing their modules.

However, a few positive points did emerge from this experience. The first of which involved the faculty of education initiating a drive for all staff to report to their line managers on a weekly basis on what work they have covered and what problems they were experiencing. As the subject leader for the History subject group, these weekly reports were sent to me. I would monitor every lecturer's performance, and where they indicated that they had issues, I would try my best to assist. An example came from when a colleague needed assistance with video compression, and I quickly recorded a video explaining which software to use and even gave an example on the steps to take. Nevertheless, we do not live in a perfect world, and this shift to online teaching brought with it numerous problems. This next section will look at some of the more challenging issues, as well as how the History subject group worked around them.

\section{What could have worked better?}

Regarding the LMS, what did not work right away was the bottleneck created when all lecturers were told that they had to use the LMS for all of the content uploading and resources for students. The LMS could only handle a set number of users at one time, and when several thousand students were trying to access the LMS concurrently at the same time, the server crashed, on more than one occasion. This made working online a literal nightmare, as the IT department was working night and day to free up more space for resources. Fortunately, this issue was resolved in a few weeks.

It might be useful to have training sessions with some of the lecturers, as certain LMS platforms are still not used to optimize efficiency, for instance, post forums, to allow the students to reply on queries (Ip et al., 2000). Using the question method in the lesson and apply a mark to it and make sure students understand it. This will enable students to work on and report on the details.

Some functions of the LMS worked better than others. For example, the chat room was indispensable, but the test functionality was extremely limiting. The only types of questions that could be asked were all lower order cognitive questions, such as multiple choice, match the columns or true and false. For a History lecturer, this is as good as dirt. We work with sources and require deep analysis and argumentation. This would not be sufficient for my needs. I used a Dropbox tool within the LMS, which fortunately has Turnitin 
functionality, to scan students' essays for plagiarism. I therefore completely avoided the test function, and instead asked the usual essay questions. However, I adapted to a sourcebased essay approach, where I would also include snippets of sources (to avoid copyright infringement) to better assist students who do not have access to data or devices to look for more resources. This solved my assessment problem.

Regarding the video recordings, despite the compression solution working well in the beginning, several students still complained that even a $30 \mathrm{MB}$ video recording was still too large and was eating up their data at a fast rate. Another idea was needed here. Fortunately, and even for the rest of the year, we as the History subject group formulated a novel approach of imbedding voice overs, very small and short 30 second snippets of a voiceover per slide. These voiceovers, however of a lower audio quality (somewhere between $64 \mathrm{~kb} / \mathrm{s}$ to $128 \mathrm{~kb} / \mathrm{s}$ ), were still audible enough, and considerably reduced the size of the recordings, from between $30 \mathrm{MB}$ to $50 \mathrm{MB}$ for the older recordings, to a much smaller $1 \mathrm{MB}$ to $3 \mathrm{MB}$. The students were very satisfied with this new approach. As can be seen from the example below, on the left, the audio of the entire 20 -minute presentation was reduced to $2.92 \mathrm{MB}$, compared to the original MP4 that was compressed to $329 \mathrm{MB}$.

\section{Compression of video presentation}

When it came to assessment, at the very least, the activities remained unchanged. However, what did change was the medium of how it should be marked. Normally, we as the History subject group would always use our LMS for assignment submission through Turnitin, which is a similarity index tool. So, moving to an online teaching mode did not alter this
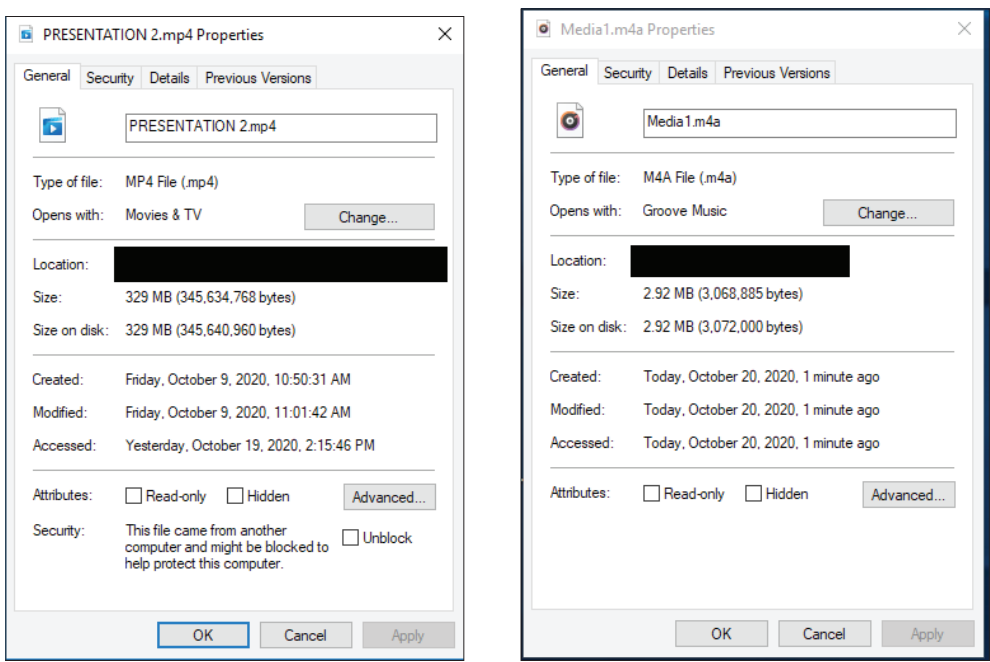
practice in the slightest. Our students are used to converting essays to PDF and to submit online to the LMS. However, the issue came from the lecturer's side... the marking. Under normal conditions, the students would in tandem submit a hard copy of their essays, along with the digital submission. Due to COVID-19 restrictions, the campus was completely shut down, and there was no way the students could submit a physical copy. Therefore, the only answer was somehow to mark the essay digitally. At this stage, no one had an answer for this. Should we just read it digitally, and without making any comments, just award a mark? This did not work for our subject group. More than $95 \%$ of my students submitted their tasks and uploaded to the LMS before the due date. However, as with any module, there are always stragglers, who would email me with several excuses. This happens even in the face-to-face traditional paradigm, so this was not really a problem. The marking of these assessments, at first, were seen as a frustration due to the significant amount of time it took to assess digitally.

Fortunately, we have some technology experts in the group, who all sat together to discuss a way forward. What we came up with would really help the entire faculty, as we decided to use the comment functionality of Adobe Acrobat reader, the PDF reader. Once the student essays were downloaded from Turnitin, those PDF reports would be assessed in Adobe using annotated comments. As a lecturer, you could change the colour of the text to red, to simulate the normal marking experience. Adding text comments helped provide proper quality feedback to students at specific points in the essay. Since the Turnitin report was marked, the plagiarism detection would also be visible, giving another layer of feedback to the student. Check marks could also be cut and pasted at certain points. Totals could be enlarged on the first page with borders, to give the student their final mark. Digital signatures could also be used, to add another layer of accountability. However, the overall procedure of adding comments and typing out the final mark, when compared to doing it by hand, took far too long to do digitally. We made our suggestions to the faculty and to the IT department. They are in the process of developing a streamlined one button solution to mark PDFs in the near future.

Regarding accountability, some negative issues did emerge. Moderation became an issue. Due to the fact that the NWU has 3 campuses, most of the History modules presented via online teaching were all aligned across these campuses. That meant that planning for the semester was done in collaboration with all module presenters. All of our assessment tasks were identical, and the weighting was the same. We could use Google docs to synchronously edit our planned assignments. However, another issue emerged. We could moderate the planning stage; however, the moderation of marked assignments was still an 
issue. I led a drive to initiate a post moderation strategy in my subject group. After using the Adobe comments, $10 \%$ of those marked assignments would be uploaded to Google Drive, whereupon a link would be sent to the module lecturers on the other campuses. Again, using the comment function in Adobe, and changing the colour to green, we were all able to moderate one another's work. Once again, the issue of time was raised. Hopefully we will solve this problem with the new PDF marking tool that is currently under development.

In terms of the ideal plans that the History subject group put in place, the idea of using recordings backfired, and therefore planning had to change immediately. Digital assessment using Adobe was thought of as the ideal idea for marking, but also turned out to be very painstaking and slow. Therefore, new plans were also put into place, allowing lecturers to print out hard copies on campus in order to mark by hand. The main thinking behind this idealistic planning was primarily drawn from those examples found in other institutions internationally that had already used online teaching before. The best solutions were taken from those examples, where it was innocently but sincerely hoped that those experiences could fit and work in a South African context. We were obviously completely oblivious at the time. The South African context is vastly different, requiring a nuanced approach concerning asynchronous sessions as opposed to synchronous live broadcasts, as the data limitations made this virtually impossible with students in rural areas. The other major reality was that the South African context required low immediacy and low access. Therefore, the deadlines need to be flexible, and the access to learning material should be standard and not require additional software or hardware. Consequently, several adaptations and adjustments had to be made on the fly so to speak, as the problems were coming in, new plans had to be made. These will be discussed in the next section.

\section{What has changed in terms of my practice?}

In terms of my practice as a History lecturer, several things had to change with the move to online teaching. Firstly, my daily routine changed dramatically working from home. A paradigm shift of note in terms of trying to juggle work time and off time, family time (especially in the beginning of the lockdown, where everyone was at home), and just trying to get by, day to day. I tried to make shifts work at first, taking an hour to work in the morning, and then take another hour break spending time with my family. This however did not always pan out properly, when urgent meetings scheduled at the $11^{\text {th }}$ hour had to be attended for further clarity on what to do. Therefore, I decided to take it a day at a 
time, meaning that certain days the routine would be different, depending on the workload. However, every day I would take a 2-hour break if I could during lunch, just to refresh my mind.

Secondly, another major change to my practice came with how I manage my work time, and what I was working on. Never before did I invest so much time in communicating with my students as I have before with face-to-face teaching. It was crucial to constantly monitor the chat room on the LMS daily, and sometimes more than once a day, especially in the build up to submission of assignments. Sometimes, the chat room would not work ideally, for instance the LMS would crash due to too many students logging in simultaneously. Therefore, I created a WhatsApp group for each module and shared the link to the group on the LMS. This really worked for me, but not necessarily for everyone. I monitored the group daily, clarifying certain aspects as needed. This was a total change, and the students have told me on several occasions that they prefer this type of communication, instead of either emailing directly, or talking to me face-to-face in the office.

A third change to my practice was the turnaround time for feedback, and how that affected my marking, especially with the aforementioned digital marking. In the beginning, before I got into the rhythm of doing things with Adobe, I would mark into the early hours of the morning, which several of my colleagues also reported doing in the early days of the shift to online teaching. This was not a healthy option, so what I did instead was to communicate to my students that they could submit their essays early, and those who submitted before the others, I would digitally mark their work first. Basically, it turned into a daily routine to check the assignments, and start marking small batches of early bird submissions, which worked wonderfully.

Fourthly, the manner in which I present content, and then either video record or use voice overs, had to change in terms of the depth I would go into. Time was a precious resource, and several other lecturers started complaining that their students were not able to download large presentations, or even worse, that their students were not paying attention to an hour-long recording, which makes perfect sense. To bore students with such long presentations is counterproductive. Instead, my practice changed to splitting up my study units into smaller chunks, whereupon I would do voice overs for that part, which would not be longer than 10 to 15 minutes each. Every week, my practice changed to doing these voice overs and uploading them on the LMS. I would then also facilitate discussions in the chatroom each week for these study unit chunks. This was totally different to the hour and a half contact session during normal face-to-face instruction, but it worked well. 


\section{Conclusion}

Online teaching is not just taking your PowerPoints and presenting them in the same way as you would during contact sessions. Put yourself in the shoes of your students. They are at home, their attention span may fall drastically, and they may not have access to platforms for which loads of data are required. Thus, all video and audio recordings should be shorter than those for a traditional class should and ought to be accessible on LMS. Try to engage your students, get them involved as much as you can with online forums, discussion, chat groups (LMS, WhatsApp, and Telegram).

Effective and continuous contact is the most critical feature of a successful online teaching environment. If the students realize what is going on and what is required of them, they will not slip back or feel confused. Communicate with students and assist them. This is a fresh opportunity for contact students. They are going to feel confused, they are going to have a ton of concerns, so whether we lend much needed guidance as lecturers or with the aid of Supplemental Instructors leaders, they are going to have a greater chance of success. 


\section{References}

Bloomer, MJ, Cross, W, Endacott, R, O’Connor, M, \& Moss, C 2012. Qualitative observation in a clinical setting: Challenges at end of life. Nursing \& Health Sciences, 14: 25-31.

Brindley, JE, Blaschke, LM, \& Walti, C 2009. Creating effective collaborative learning groups in an online environment. International Review of Research in Open and Distributed Learning, 10(3).

Carroll, K, Iedema, R, \& Kerridge, R 2008. Reshaping ICU ward round practices using video-reflexive ethnography. Qualitative Health Research, 18: 380-390.

Codreanu, A, \& Vasilescu, C 2013, 'E-learning behaviors and their impact on andragogy' in The International Scientific Conference eLearning and Software for Education;126, "Carol I” National Defence University, Bucharest, Romania.

Cronin, C 2014. Using case study research as a rigorous form of inquiry. Nurse Researcher, 21(5), 19-27.

Dhawan, S, 2020. Online learning: A panacea in the time of COVID - 19 crisis. Journal of Educational Technology Systems, 49(1):5-22.

Ellingson, LL, \& Ellis, C 2008. Autoethnography as constructionist project. In Holstein, J \& Gubrium, JF (eds), Handbook of constructionist research. New York, NY: Guilford.

Ellis, C 2004. The Ethnographic I: A methodological novel about autoethnography. Walnut Creek: AltaMira Press.

Fırat, M, Kılınç, H and Yüzer, TV 2018. Level of intrinsic motivation of distance education students in e-learning environments. Journal of Computer Assisted Learning, 34(1):6370.

Forsyth, R, Carroll, K, \& Reitano, P 2009. Introduction. International Journal of Multiple Research Approaches, 3: 214-217.

Fraillon, J, Ainley, J, Schulz, W, Duckworth, D, \& Friedman, T 2019. IEA international computer and information literacy study 2018 assessment framework. Springer Nature.

Furlong, M 2010. Clear at a distance, jumbled up close: Observation, immersion and reflection in the process that is creative research. In P. Liamputtong (Ed.), Research methods in health: Foundations for evidence-based practice. South Melbourne, Australia: Victoria Oxford University Press. 
Grieve, R, Padgett, CR, \& Moffitt, RL 2016. Assignments 2.0: The role of social presence and computer attitudes in student preferences for online versus offline marking. The Internet and Higher Education, 28:8-16.

Han, S, \& Hill, JR 2006, 'Building understanding in asynchronous discussions: Examining types of online discourse', Journal of Asynchronous Learning Networks, 10(4): 29-50.

Hartsell, T, \& Yuen, SCY 2006. Video streaming in online learning. AACE Journal, 14(1): $31-43$.

Hayano, D 1979. Auto-ethnography: Paradigms, problems and prospects. Human Organization, 38(1): 99-104.

Hodges, C, Moore, S, Lockee, B, Trust, T \& Bond, A 2020. The difference between emergency remote teaching and online learning. Educause Review, 27:1-12.

Iedema, R, Merrick, ET, Rajbhandari, D, Gardo, A, Stirling, A, \& Herkes, R 2009. Viewing the taken-for-granted from under a different aspect: A video-based method in pursuit of patient safety. International Journal of Multiple Research Approaches, 3: 290_ 301.

Ip, A, Morrison, I, Currie, M, \& Mason, J 2000. Managing online resources for teaching and learning. In The Web: communication and information access for a new millennium: proceedings of AusWeb2K, the Sixth Australian World Wide Web Conference. Southern Cross University.

Kozma, RB 2011. "ICT, Education Transformation, and Economic Development: An Analysis of the US National Educational Technology Plan.” E-Learning and Digital Media 8 (2):106-120.

Lamy, M, \& Hampel, R 2007. Online communication in language learning and teaching. Springer.

Mahaye, NE 2020, 'The Impact of COVID - 19 Pandemic on Education: Navigating Forward the Pedagogy of Blended Learning', https://www.researchgate.net/ project/The - Impact - of - COVID - 19-Pandemic - on-South-AfricanEducation — Navigating — Forward — the-Pedagogy_of_Blended_Learningdagogy. Accessed 16 November 2020.

Maréchal, G 2010. Autoethnography. In A. J. Mills, G. Durepos \& E. Wiebe (eds), Encyclopedia of case study research-. Thousand Oaks, CA: Sage Publications.

Masie, E 2002, 'Blended learning: The magic is in the mix. The ASTD e-learning handbook, 58:63. 
Mays, N, \& Pope, C 1995. Observational methods in health care settings. British Medical Journal, 311(6998):182-184.

McFarlane, AE 2019. "Devices and Desires: Competing Visions of a Good Education in the Digital Age." British Journal of Educational Technology 50(3):1125-1136.

Meyer, KA, \& Murrell, VS 2014. A national study of training content and activities for faculty development for online teaching. Journal of Asynchronous Learning Networks, 18(1): n1.

Mulhall, A 2003. In the field: Notes on observation in qualitative research. Journal of Advanced Nursing, 41:306-313.

Murphy, E \& Dingwall, R2007. Informed consent, anticipatory regulation and ethnographic prac-tice. Social Science and Medicine 65:2223-34.

Quinlan, E 2008. Conspicuous invisibility: Shadowing as a data collection strategy. Qualitative Inquiry, 14:1480-1499.

Rosenberg, MJ \& Foshay, R 2002. E-learning: Strategies for delivering knowledge in the digital age. Performance Improvement, 41(5):50-51.

Salas-Morera, L, Arauzo-Azofra, A, \& García-Hernández, L 2012. Analysis of online quizzes as a teaching and assessment tool. Journal of Technology and Science Education, 2(1):39-45.

Selwyn, N 2012. Education in a Digital World: Global Perspectives on Technology and Education. New York, London: Routledge.

Shahabadi, MM \& Uplane, M 2015, 'Synchronous and asynchronous e-learning styles and academic performance of e-learners', Procedia-Social and Behavioral Sciences, 176(20): 129-138.

Subandi, S, Choirudin, C, Mahmudi, M, Nizaruddin, N \& Hermanita, H 2018, Building interactive communication with Google classroom, International Journal of Engineering \& Technology, 7(2.13): 460-463.

Walshe, C, Ewing, G, \& Griffiths, J 2012. Using observation as a data collection method to help understand patient and professional roles and actions in palliative care settings. Palliative Medicine, 26:1048-1054.

Weaver, D, Spratt, C, \& Nair, CS 2008. Academic and student use of a learning management system: Implications for quality. Australasian journal of educational technology, 24(1).

Zenger, J \& Uehlein, C 2001, Why blended will win, Training \& Development, 55(8):5462. 
